\title{
VOZEAMENTO DO MORFEMA -S DO INGLÊS POR APRENDIZES BRASILEIROS: A INFLUÊNCIA DE RE- GRAS FONOLÓGICAS DA L1 SOBRE A L2
}

Carina S. Fragozo

(USP)

\section{RESUMO}

Este trabalho busca investigar a aquisição do vozeamento do morfema -s do inglês por falantes de português brasileiro (PB). A regra de assimilação de vozeamento, que se caracteriza pela extensão do traço [voz] de um segmento para outro segmento adjacente, ocorre tanto no PB quanto no inglês, mas de maneira distinta. Enquanto no PB a assimilação é regressiva, pois é desencadeada pelo vozeamento do contexto seguinte (ex: de[z]de, pa[s]tel), no inglês é progressiva, pois ocorre em decorrência do contexto precedente (ex: $\operatorname{dog}[\mathrm{z}]$, cat[s]). A pesquisa conta com uma amostra de $30 \mathrm{fa}-$ lantes de inglês como L2 divididos em três níveis de proficiência (básico, intermediário e avançado), além de 7 falantes nativos de inglês (grupo de controle). Os dados foram coletados através de um experimento contendo 60 palavras do inglês com a fricativa /z/ em posição final inseridas em frases, as quais foram lidas pelos sujeitos e verificadas acusticamente. Os resultados mostraram que a aplicação do vozeamento foi favorecida por segmentos vozeados no contexto seguinte, uma evidência de que é o vozeamento do contexto seguinte, e não do precedente, que estaria influenciando a produção de fricativas vozeadas nos contextos em análise. Isso é confirmado se considerarmos que o vozeamento foi aplicado em apenas $1 \%$ dos casos de fricativa seguida de consoante desvozeada ou de pausa (12/1121), contextos em que a assimilação regressiva não poderia ocorrer. Os resultados indicaram, portanto, uma transferência da regra da L1 para a L2, pois os sujeitos aplicaram a assimilação regressiva, característica do português, nos três níveis de proficiência.

PALAVRAS-CHAVE: Aquisição de L2; Regra Fonológica; Assimilação de Vozeamento 


\section{1 lntrodução}

O processo de assimilação de vozeamento, que consiste na extensão do traço [voz] de um segmento para outro segmento adjacente, ocorre tanto no Português Brasileiro (PB) quanto no inglês, mas de maneira diferente. No $\mathrm{PB}$, a fricativa /s/ em posição de coda sofre um processo de assimilação de vozeamento regressiva diante de segmento vozeado. Nesse contexto, a fricativa é produzida sistematicamente como vozeada $([\mathrm{z}]$ ou seu alofone [3], em dialetos como o carioca), pois assimila o traço [voz] do segmento seguinte. Essa regra, que é consenso nos estudos em fonologia do PB (BISOL, 2005; MATTOSO CÂMARA JR., 1972), ocorre tanto dentro de palavras quanto entre palavras (ex: me[z]mo, de[z]de, o[z] animais) e não é bloqueada por nenhum domínio prosódico específico, sendo evitada apenas em situações de pausa (cf. SILVA, 2010).

O inglês, por sua vez, apresenta dois tipos de assimilação de vozeamento: a regressiva e a progressiva. A assimilação regressiva ocorre quando fricativas sofrem dessonorização diante de obstruintes surdas (ex: five tons: fai[f] tons]) (cf. ROCA E JOHNSON, 1999). Já a assimilação progressiva ocorre em três contextos morfológicos específicos: nos morfemas de plural, do caso genitivo e da $3^{\text {a }}$ pessoa do Presente Simples. Esses morfemas, que apresentam a mesma forma básica $\{z\}$ (GUSSENHOVEN \& JACOBS 1998, p. 46), são produzidos como [s] quando precedidos de segmentos não vozeados (ex.: cat [s], Pat' [s], work [s]) e como [z] quando precedidos de segmentos vozeados (ex.: $\operatorname{dog}[z]$, John' [z], live [z])

Trabalhos como o de LOMBARDI $(1999$, p. 6) mostram que a assimilação regressiva é muito comum nas línguas do mundo e ocorre de forma sistemática. No português, regras como harmonia vocálica, palatalização e nasalização são exemplos de assimilação regressiva, pois é o contexto seguinte que desencadeia esses processos. A assimilação progressiva, por outro lado, é descrita pela autora como um processo raro e geralmente restrito a contextos morfológicos ou fonológicos específicos. No inglês, como vimos, a assimilação de vozeamento progressiva é restrita aos morfemas de plural, de terceira pessoa do singular e do caso genitivo.

Tendo esse cenário em mente, o objetivo deste trabalho é analisar a aquisição da regra de vozeamento do inglês por falantes brasileiros, de modo a verificar se é possível modificar uma regra fonológica que existe em ambas as línguas, mas de maneira diferente. Mais especificamente, 
busca-se verificar se os aprendizes aplicarão a regra de assimilação de vozeamento regressiva, característica do português, ou progressiva, característica do inglês. Dado que se trata de uma discussão sobre aquisição de L2 ${ }^{1}$, também analisaremos se o nível de proficiência traz consequências para a aquisição/aprendizado desta regra.

A hipótese a ser testada nesta pesquisa é a de que a regra fonológica da língua materna (L1) terá uma influência na aquisição da segunda língua (L2). As predições, a partir disso, são: i. Haverá mais aplicações do vozeamento nos casos de fricativa diante de contexto sonoro, por transferência da regra de assimilação regressiva do PB para o inglês; e ii. Os falantes de nível avançado apresentarão mais aplicações do vozeamento nos contextos que não permitem a assimilação regressiva do que os de nível básico e intermediário.

\section{Papel da L1 na Aquisição Fonológica de L2}

Desde os primeiros trabalhos desenvolvidos na área da aquisição de L2, a transferência de aspectos da língua materna para a língua-alvo é considerada uma influência importante durante o processo. De acordo com MAJOR (2008), o papel da transferência na aquisição de L2 já era mencionado no trabalho de TRUBETZKOY (1939), mas foram os trabalhos de FRIES (1945), WEINREICH (1953) e LADO (1957) que deram início ao desenvolvimento da Hipótese da Análise Contrastiva (Contrastive Analysis Hypothesis). Segundo essa hipótese, os aspectos da L2 que são parecidos com a L1 seriam mais fáceis de adquirir do que os que são diferentes.

Segundo autores como BROSELOW E KANG (2003), há dois problemas em afirmar que os erros cometidos por aprendizes de L2 são causados exclusivamente por transferência. O primeiro é que, em muitos casos, determinadas estruturas que não existem na L1 são mais facilmente adquiridas do que outras também inexistentes na L1, independentemente das características da L1 ou da L2. O segundo problema é que, apesar de a fala dos aprendizes de L2 apresentar padrões coerentes e sistemáticos, esses padrões são muitas vezes diferentes daqueles na L1 ou na L2. Segundo as autoras, esses dois fenômenos têm sido atribuídos a fatores universais como a marcação, em que fenômenos marcados são mais complexos e incomuns nas línguas do mundo do que os não marcados.

O conceito de marcação passou a ser utilizado na aquisição de L2 a partir do trabalho de ECKMAN (1977), que propôs a Hipótese da Mar- 
cação Diferencial (Markedness Differential Hypothesis). Essa hipótese é uma extensão da Hipótese de Análise Contrastiva e tem como objetivo identificar o grau de dificuldade na aquisição de determinada propriedade da L2 com base na L1, o qual pode ser previsto da seguinte forma:

1) as áreas da língua-alvo que diferem da língua materna e são mais marcadas do que na L1 serão mais difíceis;

2) o grau relativo de dificuldade das áreas da língua-alvo que são mais marcadas do que na L1 corresponderá ao grau relativo de marcação;

3) as áreas da língua-alvo que diferirem da língua materna, mas que não forem mais marcadas do que aquelas na L1, não serão difíceis. (ECKMAN, 1977, p. 321)

Assim, é possível prever que os fenômenos não marcados são adquiridos mais facilmente do que os marcados, ainda que nenhum deles ocorra na L1. Isso também explicaria os casos em que a fala do aprendiz apresenta características que não pertencem nem à L1 e nem à L2, o que pode ser analisado como resultado de uma preferência universal por estruturas menos marcadas. Tomemos o vozeamento de fricativas coronais, que caracterizam o foco deste trabalho, como exemplo: neste caso, os segmentos contendo o traço [+voz] seriam classificados como marcados, enquanto os que contém o traço [-voz] seriam considerados não-marcados. A Hipótese da Marcação Diferencial permite prever, então, que um falante de uma língua como o inglês, que possui o contraste de vozeamento entre /s/ e /z/ em posição final (ex: ice vs. eyes), não terá dificuldade em produzir palavras no português, que não apresenta esse contraste fonológico. Um falante de português adquirindo o inglês, por outro lado, deverá aprender a fazer esse contraste, que é uma estrutura mais marcada do que na sua L1 (GASS e SELINKER, 2009).

Além da marcação, os graus de similaridade/dissimilaridade são aspectos relevantes no que diz respeito à transferência da L1 para a L2. Diferentemente do que LADO (1957) previa com a Hipótese da Análise Contrastiva, MAJOR (2001) propõe que os sons que forem similares na L1 e na L2 são mais difíceis de serem adquiridos do que aqueles que são dissimilares. A similaridade dificultaria a tarefa do aprendiz de desenvolver novas categorias fonológicas para sons tão semelhantes nas duas línguas. Nesses casos, a tendência é que o aprendiz aplique o padrão da 
L1 em vez de desenvolver a categoria correspondente da L2. A questão central nessa proposta é, portanto, definir o conceito de similaridade. Segundo o autor, fatores como percepção, informações acústicas e articulatórias e até a intuição de falante nativo podem ser determinantes para identificar o grau de semelhança entre determinado som na L1 e na L2.

A questão da similaridade na percepção de sons não nativos também foi apontada em FLEGE (1995). Através do Speech Learning Model, o autor propõe que é possível prever a dificuldade na aquisição de sons não-nativos de acordo com o grau de similaridade entre os sons da L1 e da L2. O modelo prevê que sons da L2 idênticos aos da L1 serão adquiridos com facilidade, sons da L2 que são muito diferentes da L1 serão adquiridos com um pouco menos de facilidade, e os sons da L2 que são parecidos, mas não são idênticos aos da L1, serão os mais difíceis de serem adquiridos. Em outras palavras, é necessário um certo grau de dissimilaridade entre os sons da L1 e os da língua-alvo para que o aprendiz seja capaz de perceber o contraste. Assim, nos casos em que os sons são parecidos, mas não idênticos, o aprendiz tende a processar o som da L2 numa categoria perceptual da L1.

Os resultados da pesquisa de MENDES (2017) mostram evidências de que a percepção pode, de fato, ser um fator determinante para a produção de fricativas vozeadas em posição final no inglês. $\mathrm{O}$ autor investigou a percepção do morfema -s do inglês por 33 aprendizes brasileiros, observando o papel do contexto fonológico seguinte, o tempo de tarefa, o nível de confiança, e o nível de proficiência dos sujeitos. Os resultados encontrados pelo autor mostraram que, dentre os três alomorfes testados ([s], [z] e [Iz]), o [z] foi o que apresentou a taxa de acertos mais baixa, de $39 \%$, ou seja, os participantes tiveram dificuldade de identificar o $[\mathrm{z}]$ em posição de final de palavra, a não ser nos casos de contexto seguinte vozeado.

A partir do que foi discutido nesta seção, busca-se, portanto, investigar a influência do português no percurso de aquisição do inglês no que diz respeito à regra de assimilação de vozeamento progressiva. Para isso, foram estabelecidos os critérios metodológicos que serão descritos na Seção 3 a seguir.

\section{Metodologia}

A amostra é constituída por 30 falantes de inglês como L2, 10 em cada nível de proficiência: básico, intermediário e avançado. $\mathrm{O}$ nivelamento dos participantes foi realizado através de um teste online 
baseado em questões de múltipla escolha e um teste de proficiência oral, ambos oferecidos gratuitamente no site Cambridge English, mantido pela University of Cambridge, no Reino Unido². Os critérios para a seleção dos falantes não-nativos nesta pesquisa foram os seguintes: 1) Não ter morado num país falante de inglês por mais de um mês; 2 ) ser filho de pais brasileiros monolíngues; e 3) Não falar nenhuma outra língua estrangeira além do inglês. Além desses informantes, 7 falantes nativos de inglês, que viveram a maior parte da vida em seus países de origem, foram usados como grupo de controle.

O experimento consistia na leitura de 60 palavras do inglês terminadas em /z/, inseridas em 28 frases com dois tipos de contexto fonológico: 30 palavras foram seguidas de segmento vozeado (ex: Jack live [z] $\underline{i} n$ the countryside), nos quais a fricativa poderia ser vozeada por influência da assimilação regressiva do $\mathrm{PB}$, e 30 palavras foram seguidas de segmento desvozeado ou vazio (ex: Susan read Pam '[z] paper [z]), nos quais não poderia haver influência da assimilação regressiva do português.

Os informantes foram instruídos a ler cada uma das ocorrências da maneira mais natural possível. As gravações foram realizadas com um microfone de baixa impedância da marca Behringer, um pedestal de mesa e uma placa acústica Roland Quad-capture ${ }^{3}$. A produção dos 37 informantes proporcionou um corpus de 2.220 palavras terminadas em $/ z /$.

A sonoridade das fricativas produzidas pelos informantes (voze$a d a$ - desvozeada) foi determinada através de verificação acústica com uso do software PRAAT (BOERSMA \& WEENINK, 2013). Observou-se a faixa de vozeamento localizada na parte inferior do espectrograma, a presença de pulsos glotais durante a produção da fricativa e a curva de F0, que nas fricativas sonoras se mostra contínua e nas fricativas surdas é interrompida. ${ }^{4}$

Após essa etapa de classificação, os dados foram submetidos a um teste de regressão logística realizado por meio do software Varbrul. As variáveis investigadas foram: Contexto Precedente, Contexto Seguinte, Categoria Morfológica, Nível de Proficiência e Idade de Início da Aquisição. Os fatores para as variáveis estatisticamente significativas estão descritos nos resultados a seguir. 


\section{Resultados}

Nesta seção serão apresentados os resultados referentes ao vozeamento do morfema -s do inglês. Os resultados dos 7 falantes nativos de inglês, que constituem o grupo de controle, são apresentados na Seção 4.1 a seguir. Na Seção 4.2, são apresentados os resultados referentes aos 30 falantes de inglês como L2.

\subsection{Falantes nativos de inglês}

A taxa de aplicação do vozeamento pelos 7 falantes nativos que constituem a amostra de controle nesta pesquisa pode ser observada no Gráfico 1 - todos casos em que o vozeamento seria obrigatório em inglês.

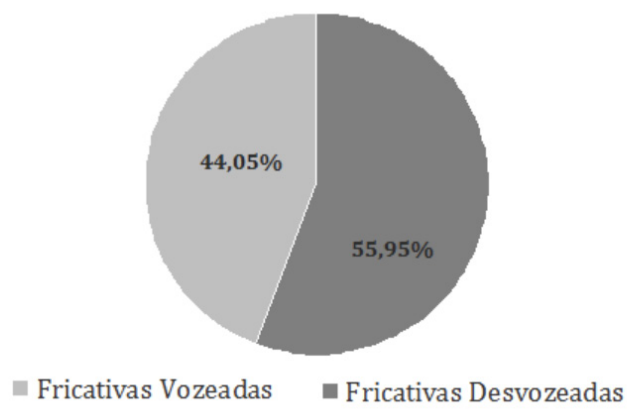

Gráfico 1: Aplicação do vozeamento por falante nativos

Conforme se pode observar, os falantes nativos produziram menos fricativas vozeadas (185/438) que não vozeadas (253/438). Dentre as três variáveis testadas neste grupo, a análise estatística apontou que apenas Contexto Seguinte influencia o vozeamento. Categoria Morfológica e Contexto Precedente, portanto, não se mostraram estatisticamente significantes nos dados dos falantes nativos desta pesquisa.

A variável Contexto Seguinte, que observa a influência de vogais (ex: loves everything), consoantes vozeadas (ex: Mary's book), consoantes desvozeadas (ex: boys play) e pausas (He bought new shoes.) sobre o vozeamento, indicou que a aplicação da regra é favorecida quando o contexto seguinte é vozeado. Pode-se observar na Tabela 1 que os contextos que favoreceram a aplicação do vozeamento foram as vogais e as consoantes vozeadas, com pesos relativos de 0,68 e 0,67 , respectivamente. Consoantes 
desvozeadas e pausas, por outro lado, não favoreceram a aplicação da regra, com pesos relativos de 0,40 e 0,31 , respectivamente, e apresentaram taxas de aplicação do vozeamento significativamente mais baixas, de $35 \%$ e $12,5 \%$.

Tabela 1 - Vozeamento e Contexto Seguinte : Falantes Nativos

\begin{tabular}{llllll}
\multirow{2}{*}{ Contexto Seguinte } & \multicolumn{2}{c}{ Vozeado } & \multicolumn{2}{c}{ Desvozeado } & PESO \\
\cline { 2 - 5 } & $\mathbf{n}$ & $\mathbf{\%}$ & $\mathbf{n}$ & $\mathbf{\%}$ & \\
\hline Vogal & 76 & 61,29 & 48 & 38,71 & 0,68 \\
Consoante Vozeada & 51 & 60,71 & 33 & 39,29 & 0,67 \\
Consoante Desvozeada & 49 & 35,00 & 91 & 65,00 & 0,40 \\
Pausa & 9 & 12,50 & 63 & 87,50 & 0,31 \\
\hline
\end{tabular}

O Gráfico 2 traz aplicação do vozeamento por informante. Percebe-se uma diferença na porcentagem de aplicação entre os nativos 1, 2, 3 e 4, que apresentaram taxas de aplicação do vozeamento mais altas $(71 \%$, $50 \%, 63,3 \%$ e $73,3 \%$, respectivamente), e os nativos 5,6 e 7 , com taxas bem mais baixas $(16,6 \%, 8,3 \%$ e $25 \%$, respectivamente). Interessantemente, os nativos 5, 6 e 7 são os únicos que nunca saíram dos Estados Unidos.

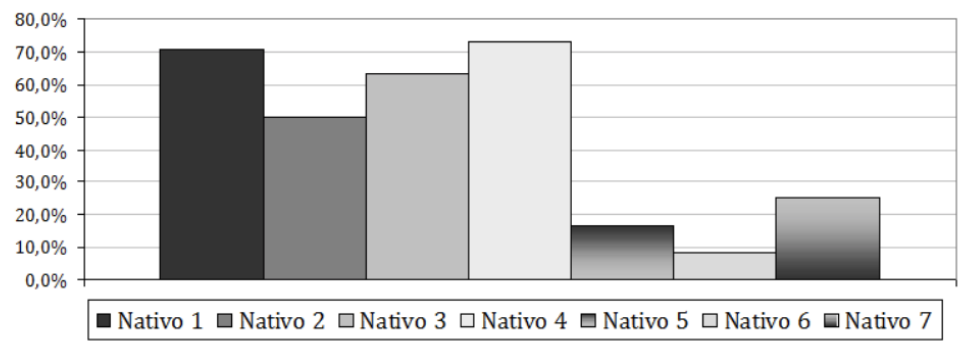

Gráfico 2 - Vozeamento por Informante: Falantes Nativos

Para verificar influência do contexto seguinte sobre a aplicação do vozeamento pelos informantes do grupo de controle foi realizado um cruzamento entre as variáveis Informante e Contexto Seguinte. Os resultados 
mostraram que houve um favorecimento de contextos seguintes sonoros (vogais e consoantes vozeadas) sobre o vozeamento da fricativa na produção de todos os falantes nativos, exceto o Nativo 6. O Gráfico 3 apresenta a taxa de aplicação do vozeamento em cada um dos quatro tipos de contexto seguinte.

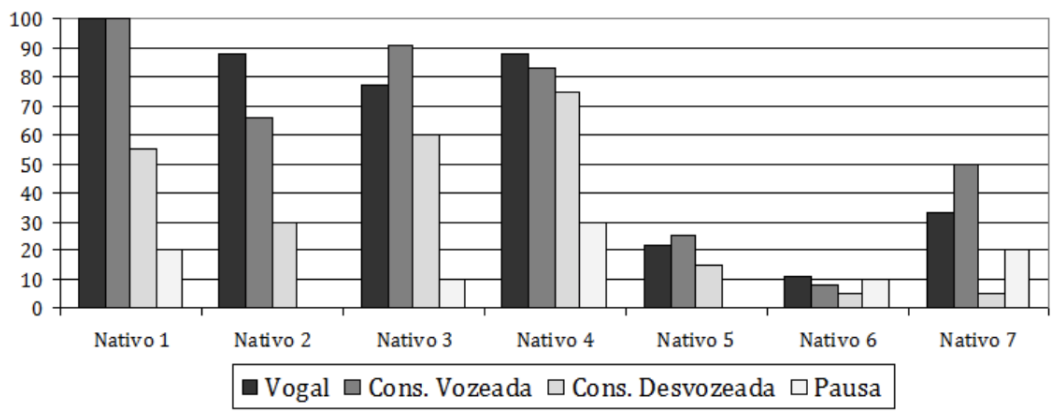

Gráfico 3: Aplicação do vozeamento por contexto seguinte - Falantes Nativos

Pôde-se observar, portanto, que a taxa de aplicação do vozeamento é superior quando o contexto seguinte é sonoro (vogal ou consoante vozeada) e que esse resultado foi estatisticamente significante no grupo de falantes nativos.

\subsection{Falantes de inglês como L2}

A taxa de aplicação do vozeamento por todos os aprendizes de inglês como L2 pode ser visualizada no Gráfico 4 - todos casos em que o vozeamento da fricativa seria obrigatório em inglês.

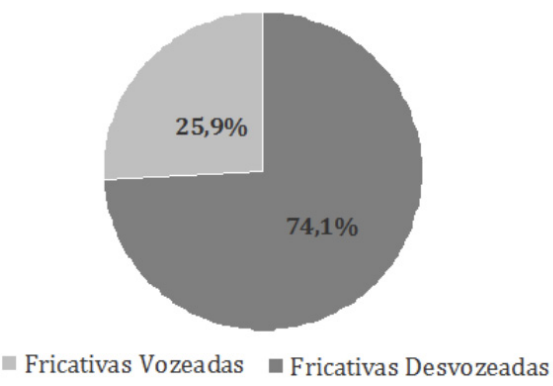

Gráfico 4: Aplicação do vozeamento por falantes de inglês como L2 
Conforme se pode observar, os participantes produziram menos fricativas vozeadas (466/1800) que não vozeadas (1334/1800). Ressaltamos que o Gráfico 4 inclui tanto contextos de fricativa seguida por um segmento sonoro, quando o vozeamento poderia ser resultado de assimilação regressiva (ex: dogs around, John's ball), quanto contextos de fricativa seguida de uma consoante surda (ex: John's cousin) ou pausa (ex: new shoes ), quando o vozeamento seria, de fato, uma evidência da aquisição da regra do inglês.

A análise estatística apontou que as variáveis Contexto Seguinte, Contexto Precedente e Nivel de Proficiência influenciam no vozeamento. Dentre as variáveis testadas, portanto, Categoria Morfológica e Idade de Início da Aquisição não se mostraram relevantes para a aplicação da regra.

A variável Contexto Seguinte, que tem por objetivo verificar a influência do contexto fonológico que sucede a fricativa na aplicação do vozeamento, foi a primeira selecionada como estatisticamente relevante. Os fatores investigados foram pausa (ex: I bought pears. ), consoante desvozeada (ex: boyfriend's father), consoante vozeada (ex: Mary's book) e vogal (ex: Jack lives in the countryside). Os resultados mostraram que, assim como no grupo de controle, as vogais e as consoantes vozeadas foram os contextos que mais favoreceram a aplicação do vozeamento, ambos com peso relativo de 0,93 . As consoantes desvozeadas, por sua vez, tiveram um peso relativo de $0,16 \mathrm{e}$, portanto, desfavoreceram a aplicação da regra. Por fim, contextos de pausa foram os que menos favoreceram o vozeamento da fricativa. A aplicação da regra neste contexto ocorreu apenas 3 vezes e apresentou peso relativo de 0,07 , conforme a Tabela 2 :

Tabela 2 - Vozeamento e Contexto Seguinte: Falantes Brasileiros

\begin{tabular}{llllll}
\multirow{2}{*}{ Contexto Seguinte } & \multicolumn{4}{c}{ Desvozeado } & PESO \\
\cline { 2 - 5 } & REL. \\
\cline { 2 - 5 } & $\mathbf{n}$ & $\mathbf{\%}$ & $\mathbf{n}$ & $\mathbf{\%}$ & \\
\hline Cons. Vozeada & 200 & 58,82 & 140 & 41,18 & 0,93 \\
Vogal & 254 & 58,12 & 183 & 41,88 & 0,93 \\
Cons. Desvozeada & 9 & 1,66 & 532 & 98,34 & 0,16 \\
Pausa & 3 & 0,62 & 479 & 99,38 & 0,07
\end{tabular}


A variável Contexto Precedente, que tem por objetivo verificar a influência do contexto fonológico que antecede a fricativa, também se mostrou significativa para a aplicação da regra no grupo de falantes de inglês como L2. Como vimos na Seção 4, todos os contextos precedentes nas palavras do experimento são vozeados (já que são os contextos em que o -s é produzido como/z/ no inglês). Os contextos testados com esta variável foram: vogais (ex: tomatoes [tə'meitouz]), nasais (ex: opens ['oupənz]), líquidas (ex: brothers [br $\Lambda$ ðrz]), fricativas sonoras (ex: loves [' $1 \Lambda \mathrm{vz}])$ e plosivas sonoras (ex: $\operatorname{dog} \underline{s}$ [dəgz]). Dentre esses contextos, vogal foi o que mais favoreceu o vozeamento, com peso relativo de 0,64 . As fricativas e as nasais, com peso relativo de $0,50 \mathrm{e}$ 0,47, respectivamente, ficaram próximas do ponto neutro, o que significa que não tiveram papel significativo sobre a aplicação do vozeamento. As plosivas e as líquidas, por fim, não favoreceram a aplicação da regra, com peso de 0,39 e 0,34 , respectivamente, conforme a Tabela 3:

Tabela 3: Vozeamento e Contexto Precedente: Falantes Brasileiros

\begin{tabular}{llllll}
\multirow{2}{*}{ Contexto Precedente } & \multicolumn{3}{c}{ Vozeado } & \multicolumn{3}{c}{ Desvozeado } & PESO \\
\cline { 2 - 5 } & $\mathbf{n}$ & $\mathbf{\%}$ & $\mathbf{n}$ & $\mathbf{\%}$ & \\
\hline Vogal & 218 & 34,6 & 412 & 65,4 & 0,64 \\
Fricativa & 73 & 34,8 & 137 & 65,2 & 0,50 \\
Nasal & 59 & 21,7 & 211 & 78,1 & 0,47 \\
Plosiva & 84 & 23,3 & 276 & 76,7 & 0,39 \\
Líquida & 33 & 10 & 330 & 90 & 0,34
\end{tabular}

A última variável que se mostrou estatisticamente relevante para a aplicação do vozeamento por falantes brasileiros foi Nivel de Proficiência, que divide os informantes entre os níveis Básico, Intermediário e Avançado. Pode-se observar na Tabela 4 que, diferentemente do esperado, os falantes de nível avançado apresentaram uma taxa de aplicação do vozeamento inferior à dos falantes de nível intermediário, com 27,33\% e $33,83 \%$, respectivamente. Os falantes de nível básico, por sua vez, apresentaram a menor porcentagem de fricativas vozeadas, de $16,5 \%$. Observa-se, também, que o nível Intermediário foi o único que favoreceu a aplicação da regra, com peso relativo de 0,59, enquanto Básico e Avançado não foram favorecedores, com pesos 0,44 e 0,45 , respectivamente. 


\begin{tabular}{|c|c|c|c|c|c|}
\hline \multirow{3}{*}{ Nível de Proficiência } & \multirow{2}{*}{\multicolumn{2}{|c|}{ Vozeado }} & \multirow{2}{*}{\multicolumn{2}{|c|}{ Desvozeado }} & \multirow{3}{*}{$\begin{array}{l}\text { PESO } \\
\text { REL. }\end{array}$} \\
\hline & & & & & \\
\hline & $\mathbf{n}$ & $\%$ & $\mathbf{n}$ & $\%$ & \\
\hline Básico & 99 & 16,50 & 501 & 83,50 & 0,44 \\
\hline Intermediário & 203 & 33,83 & 397 & 66,17 & 0,59 \\
\hline Avançado & 164 & 27,33 & 436 & 72,67 & 0,45 \\
\hline
\end{tabular}

A proporção de vozeamento em cada nível de proficiência pode ser visualizada no Gráfico 5, que apresenta também a taxa de aplicação do grupo de controle (nativos), já apresentada na Seção 4.1.

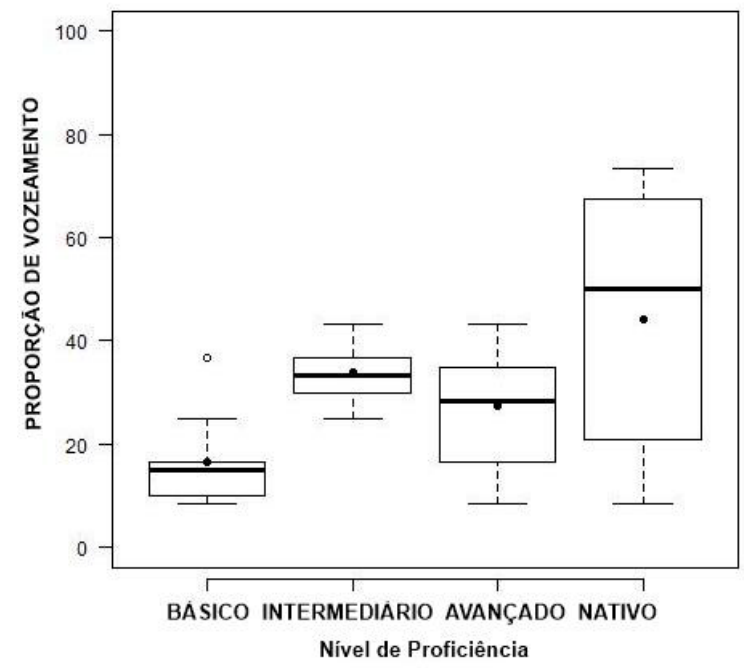

Gráfico 5: Vozeamento por nível de proficiência

Dados os resultados por nível de proficiência, apresentamos também os resultados por informante no Gráfico 6. Como se pode observar, alguns informantes tiveram uma taxa de aplicação muito baixa (e.g. Informantes 4 e 30, com apenas $8,33 \%$ ), o que certamente afeta a média dos resultados. 


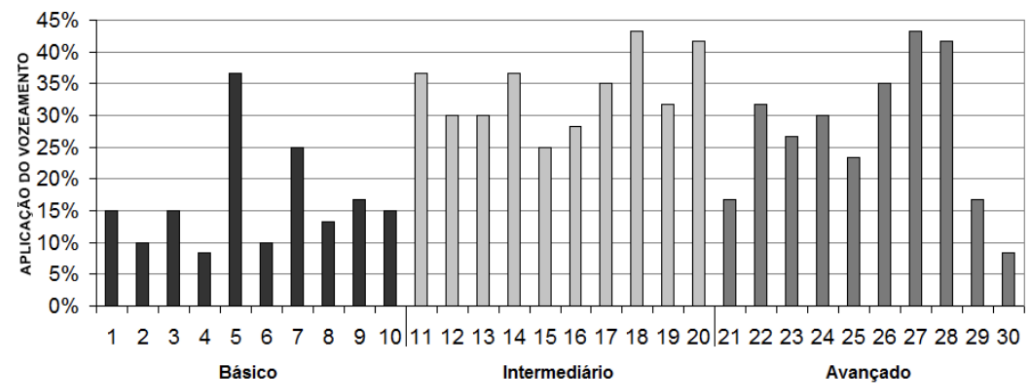

Gráfico 6: Vozeamento por Informante e Nivel de Proficiência

Observa-se que, de maneira geral, os resultados dos falantes de nível intermediário são os mais homogêneos, variando entre 25\% e 43,33\% de aplicação do vozeamento. Destacam-se, no nível intermediário, os informantes 18 e 20, que apresentaram as maiores taxas de aplicação entre os falantes deste nível ( $43,33 \%$ e $41,66 \%$, respectivamente). No caso do nível avançado, observa-se uma variação muito maior: enquanto os informantes 27 e 28 se destacam com as maiores taxas de aplicação, os informantes 21, 25, 29 e 30 apresentam taxas de vozeamento mais baixas do que qualquer falante de nível intermediário, o que contribui para a taxa geral dos informantes de nível avançado ter sido mais baixa que a dos de nível intermediário (cf. Tabela 4, Gráfico 5). Dentre os falantes de nível básico, o Informante 5 apresentou a maior taxa de aplicação do vozeamento $(36,66 \%)$, superando 8 dos 10 participantes de nível avançado. Entretanto, os outros 9 informantes de nível básico apresentaram taxas bastante inferiores às da maioria dos informantes dos outros dois níveis.

Esses resultados, contudo, não significam que a maior taxa de aplicação do vozeamento representa, de fato, a aquisição da regra de vozeamento do inglês. A alta taxa de aplicação do vozeamento por determinados informantes pode ter ocorrido por terem produzido menos pausas entre as palavras do que outros informantes e, consequentemente, aplicado a regra de assimilação regressiva, característica do português. Para verificar a aplicação do vozeamento da fricativa por informante em contextos que não favoreceriam a assimilação regressiva, ou seja, casos de fricativa seguida de consoante desvozeada (ex: John $\underline{s}$ cousin) ou pausa (ex: movies ), realizou-se um cruzamento entre as variáveis Informante e Contexto Seguinte. 
Os resultados apontaram que a grande maioria dos informantes aplicou o vozeamento apenas quando a fricativa era seguida de um segmento vozeado. Nos casos em que o contexto seguinte era uma vogal (ex: dogs around), o Informante 7, do nível básico, aplicou $87,5 \%$ de vozeamento, enquanto o Informante 2 , também do nível básico, aplicou apenas em 1 caso neste contexto (1,66\%). No caso de fricativas seguidas de consoante vozeada (ex: John's videogame), os Informantes 12 e 28, de nível intermediário e avançado, respectivamente, aplicaram o vozeamento em $91,66 \%$ dos casos (11/12), e todos os outros informantes aplicaram o vozeamento em pelo menos uma das ocorrências neste contexto.

Nos casos de fricativa seguida por consoante desvozeada (ex: kids playing) ou pausa (ex: I bought pears ), quase não houve casos de vozeamento. Pode-se observar no Gráfico 7 que apenas os Informantes 1, 3 e 6, de nível básico, os informantes 11, 14, 17 e 20, de nível intermediário, e o Informante 22, de nível avançado, apresentaram algum caso de vozeamento quando o contexto seguinte era uma consoante desvozeada. Nos contextos de fricativa seguida de pausa, ${ }^{5} \mathrm{o}$ vozeamento ocorreu em ainda menos casos: somente o Informante 20, do nível intermediário, apresentou 3 casos de vozeamento. Fica bastante claro no Gráfico 7, portanto, que o vozeamento ocorreu majoritariamente nos casos de contexto seguinte vozeado (vogal ou consoante vozeada).

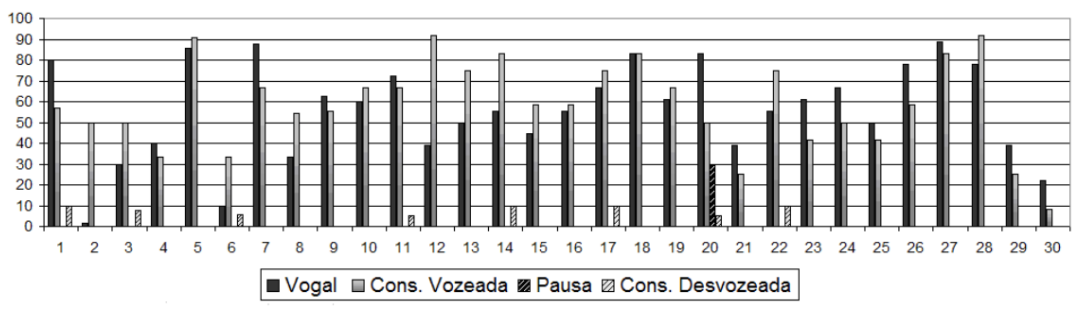

Gráfico 7: Vozeamento por Informante e Contexto Seguinte

Portanto, os resultados apresentados nesta seção mostram que, apesar de os informantes terem aplicado o vozeamento em $25,9 \%$ das ocorrências (Cf. Gráfico 4), ele ocorreu em apenas 1,17\% (12/1023) dos casos em que o contexto seguinte era um segmento desvozeado $(9 / 541)$ ou uma pausa (3/482). Isso mostra que, na grande maioria dos casos, a regra foi aplicada por influência do vozeamento do contexto seguinte, e não do contexto precedente. 
Para verificar o percurso de aquisição da regra nos contextos que não permitiam a assimilação regressiva, realizou-se o cruzamento entre as variáveis Nivel de Proficiência e Contexto Seguinte. Se observarmos na Tabela 5 apenas os casos de fricativa seguida de consoante desvozeada, que não permitem o vozeamento pela aplicação da regra do português, verificamos apenas 3 aplicações da regra no nível básico, 5 no nível intermediário e 1 no nível avançado. Nos casos de fricativa seguida de pausa, que também bloqueia a assimilação regressiva, há ainda menos aplicações do vozeamento: somente os informantes do nível intermediário apresentaram 3 casos de vozeamento. Esse resultado mostra que os casos de vozeamento foram fortemente influenciados por contextos seguintes sonoros (vogal e consoante vozeada) nos três níveis de proficiência. Se observarmos os poucos casos de aplicação do vozeamento com consoantes desvozeadas no contexto seguinte, percebemos que há mais aplicação da regra no nível básico do que no nível avançado. Nos contextos seguidos de pausa, encontramos aplicações apenas no nível intermediário.

Tabela 5 - Cruzamento entre Nivel de Proficiência e Contexto Seguinte

\begin{tabular}{|c|c|c|c|c|c|c|c|c|}
\hline \multirow{3}{*}{$\begin{array}{l}\text { Nível } \\
\text { de } \\
\text { Profic. }\end{array}$} & \multicolumn{4}{|c|}{$\begin{array}{l}\text { CONTEXTO SEGUINTE } \\
\text { VOZEADO }\end{array}$} & \multicolumn{4}{|c|}{$\begin{array}{l}\text { CONT. SEGUINTE } \\
\text { DESVOZEADO/PAUSA }\end{array}$} \\
\hline & \multicolumn{2}{|l|}{ VOGAL } & \multicolumn{2}{|c|}{\begin{tabular}{|l} 
CONS. \\
VOZEADA
\end{tabular}} & \multicolumn{2}{|c|}{$\begin{array}{l}\text { CONS. } \\
\text { DESVOZ. }\end{array}$} & \multicolumn{2}{|c|}{ PAUSA } \\
\hline & $\begin{array}{l}\text { Casos/ } \\
\text { Total }\end{array}$ & $\%$ & \begin{tabular}{|l} 
Casos/ \\
Total
\end{tabular} & $\%$ & $\begin{array}{l}\text { Casos/ } \\
\text { Total }\end{array}$ & $\%$ & $\begin{array}{l}\text { Casos/ } \\
\text { Total }\end{array}$ & To \\
\hline Básico & $41 / 86$ & 48 & $55 / 110$ & 50 & $3 / 145$ & 2 & $0 / 276$ & 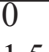 \\
\hline Interm. & $115 / 190$ & 61 & $82 / 110$ & 75 & $5 / 200$ & 2,5 & $3 / 200$ & \\
\hline Avanç & $106 / 190$ & 56 & $52 / 93$ & 56 & $1 / 200$ & 0,5 & $0 / 100$ & 0 \\
\hline
\end{tabular}

Os resultados indicam, portanto, que a aquisição do vozeamento do morfema -s do inglês não ocorreu em nenhum nível de proficiência, pois a taxa de aplicação do vozeamento em contextos que não permitiam a regra de assimilação regressiva, do português, foi extremamente baixa nos três níveis de proficiência testados.

\section{Discussão}

Os resultados apresentados em 4.1 mostraram que os falantes nativos de inglês aplicaram o vozeamento em apenas $44,05 \%$ dos casos, ainda 
que todos os contextos favorecessem a produção de fricativas vozeadas. Dois fatores podem estar influenciando esse resultado: o desvozeamento do contexto precedente e o desvozeamento do /z/ em determinados contextos fonológicos.

Durante a transcrição dos dados observou-se que, em alguns casos, as plosivas e as fricativas do contexto precedente foram produzidas como surdas. Por isso, verificamos acusticamente o contexto precedente de todas as palavras em que a fricativa não foi vozeada pelos falantes nativos e observamos que a fricativa $/ \mathrm{v} /$ foi produzida como surda em $0,7 \%$ dos casos, nas palavras loves e leaves, e as plosivas /b/ e /g/ em 31\% dos casos, nas palavras dogs, bird's, kids e boyfriend's. Nesses casos, o desvozeamento do contexto precedente resulta na aplicação da regra de assimilação de vozeamento progressiva, na qual o morfema -s é produzido como [s] quando antecedido por uma consoante surda. Assim, pelo menos nesses contextos, a baixa taxa de vozeamento pode ser explicada por esse processo de assimilação.

Além do desvozeamento do contexto precedente, o desvozeamento de fricativas fonologicamente sonoras em determinados contextos é um fator relevante para entendermos a ausência de vozeamento em mais da metade das produções dos nativos nesta pesquisa. De acordo com Smith (1997), o desvozeamento das fricativas tende a ocorrer principalmente em posição final, pois é difícil produzir a sonoridade e, ao mesmo tempo, a fricção característica dessas consoantes neste contexto. Se analisarmos os resultados apontados na Tabela 1, é justamente o que se observa nesta pesquisa: menos ocorrências de vozeamento nos casos de pausa no contexto seguinte, posição em que o esforço articulatório tende a ser reduzido (cf. SMITH, 1997). Acreditamos, portanto, que o desvozeamento do contexto precedente e o desvozeamento da fricativa em posição final são aspectos que influenciaram o fato de os nativos não terem apresentado uma taxa de vozeamento mais alta.

Retomemos, então, as nossas predições a respeito da aquisição da regra de assimilação progressiva do inglês pelos falantes brasileiros. A primeira previa que o vozeamento seria aplicado principalmente nos casos de fricativa diante de contexto sonoro, por transferência da regra de assimilação regressiva do PB para o inglês. Os resultados mostraram que a aplicação do vozeamento foi, de fato, favorecida por segmentos vozeados no contexto seguinte, e que nos casos de fricativa seguida de consoante desvozeada ou de pausa o vozeamento foi aplicado em apenas $1 \%$ dos dados $(12 / 1121)$. 
Os resultados também indicaram que a produção de fricativas vozeadas foi favorecida por vogais no contexto precedente (Cf. Tabela 6). Apesar de as fricativas serem precedidas de segmentos vozeados em todas as palavras do experimento, isso poderia indicar que, sendo a vogal o elemento mais sonoro na escala de sonoridade, ela teria uma maior influência sobre o vozeamento do segmento seguinte. Entretanto, como vimos, além de aplicação do vozeamento ter sido favorecida por segmentos vozeados no contexto seguinte, a taxa de aplicação do vozeamento em contextos que não permitiam a assimilação regressiva foi quase inexistente. Fica claro, portanto, que foi o vozeamento do contexto seguinte que influenciou a produção de fricativas vozeadas nos contextos em análise, e não o do contexto precedente.

De acordo com a nossa segunda predição, os falantes de nível avançado apresentariam mais aplicações do vozeamento nos contextos que não permitem a assimilação regressiva do que os de nível básico e intermediário, o que indicaria a aquisição da regra do inglês. Como vimos, a variável nível de proficiência foi selecionada como estatisticamente relevante, e indicou que os falantes de nível intermediário foram os que apresentaram mais casos de vozeamento - cf. Gráfico 5 na Seção 4.2.

Entretanto, é importante salientar que nível de proficiência foi estatisticamente significante apenas porque foi considerada a taxa de aplicação geral do vozeamento pelos informantes - a qual inclui os contextos em que o vozeamento poderia ser resultado de assimilação regressiva. Isso se confirma quando observamos a taxa de aplicação do vozeamento especificamente nos casos que não permitem a aplicação da assimilação regressiva, do português. O Gráfico 8 apresenta a proporção de vozeamento somente nos casos de fricativa seguida de pausa ou consoante desvozeada, separada por nível de proficiência. Pode-se observar que, nesses contextos específicos, não há um aumento na aplicação do vozeamento no decorrer do processo de aprendizagem, já que todos os níveis apresentam uma taxa de aplicação muito baixa e muito aproximada. 


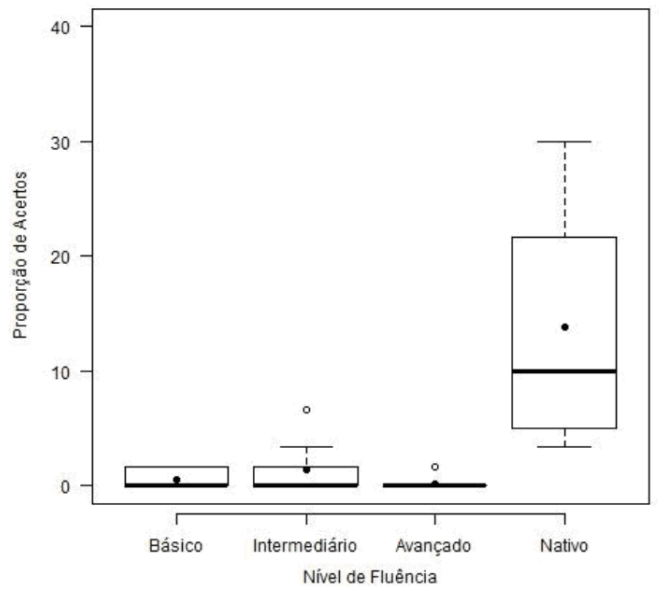

Gráfico 8: Aplicação do vozeamento em fricativas seguidas de pausa ou de consoante desvozeada por nivel de proficiência

Portanto, ainda que o nível intermediário tenha apresentado mais aplicações de vozeamento do que os informantes dos outros dois níveis, não podemos afirmar que a regra de vozeamento do inglês foi adquirida em nenhum nível de proficiência se olharmos somente para os casos que não permitiam a assimilação regressiva. Percebe-se, portanto, uma transferência da regra fonológica da L1 para a L2 nos três níveis de proficiência.

\section{Considerações Finais}

$\mathrm{Na}$ presente pesquisa, buscou-se verificar a aquisição da regra de vozeamento do morfema -s em inglês por falantes brasileiros, com base na hipótese de que haveria uma transferência da regra de assimilação regressiva, do português, para a língua-alvo. Tal hipótese foi confirmada, pois a grande maioria dos casos de vozeamento da fricativa nos contextos analisados se deu quando o contexto seguinte era vozeado (vogal ou consoante vozeada), o que desencadeou a aplicação da regra do português. Nos casos de fricativa seguida de pausa ou de consoante desvozeada, quando a regra do português não poderia ser aplicada, as ocorrências de vozeamento foram quase inexistentes nos três níveis de proficiência. Fica claro, portanto, não só que a regra de vozeamento do inglês não foi adquirida pelos informantes desta pesquisa, mas também que não há um 
percurso de desenvolvimento da regra no processo de aprendizagem, já que não houve diferenças significativas no vozeamento em contextos que não favoreciam assimilação regressiva em nenhum nível de proficiência.

\section{VOICING OF THE ENGLISH -S MORPHEME BY BRAZILIAN LEARNERS: THE INFLUENCE OF PHO- NOLOGICAL RULES OF THE L1 ON THE L2}

This work aims at investigating the acquisition of the English -s morpheme voicing by speakers of Brazilian Portuguese (BP). Voicing assimilation, which consists of extending the [voice] feature from one segment to another, occurs both in BP and in English, but in a different way. While in BP the assimilation is regressive, since it is triggered by the voicing of the following context (e.g.: me[z]mo), in English it is progressive, as it occurs due to the preceding context (e.g.: $\operatorname{dog}[\mathrm{z}]$, cat[s]). The sample is composed of 30 Brazilian speakers of English as a second language divided into three proficiency levels (basic, intermediate and advanced), plus 7 native English speakers (control group). The data were collected through an experiment containing 60 words with the fricative $/ z /$ in final position, which were read by the subjects and acoustically verified. The results showed that the application of voicing was favored by voiced segments in the following context, an evidence that it is the voicing of the following context, rather than the preceding one, that influenced the production of voiced fricatives in the contexts under analysis. This is confirmed if we consider that voicing was applied in only $1 \%$ of cases of fricative followed by voiceless consonants or pauses (12/1121), contexts in which regressive assimilation could not occur. Therefore, the results showed a transference of the $\mathrm{L} 1$ rule to the $\mathrm{L} 2$, since the subjects applied the regressive voicing assimilation in the three proficiency levels.

KEYWORDS: L2 Acquisition; Phonological Rule; Voicing Assimilation 


\section{NOTAS}

${ }^{1}$ Este trabalho não faz distinção entre os termos "língua estrangeira" e "segunda língua" (L2).

${ }^{2}$ www.cambridgeenglish.org

${ }^{3}$ Com exceção de 3 falantes nativos de inglês, que moram nos Estados Unidos. Nesses casos, os dados foram coletados a distância, com o gravador Olympus VN120 Digital Rec.Bulk, mas obedecendo os mesmos critérios estabelecidos para os outros 34 participantes da pesquisa.

${ }^{4}$ Em alguns casos, a distinção entre fricativas vozeadas e desvozeadas não ficou clara, já que os participantes produziram metade da consoante vozeada e a outra metade desvozeada. Apesar de o vozeamento ocorrer apenas na primeira metade da consoante, as fricativas produzidas dessa forma foram, perceptualmente, identificadas como vozeadas. Portanto, optou-se por classificar essas ocorrências como "vozeadas" por dois motivos: 1) há uma indicação de vozeamento, ainda que parcial; 2) essas fricativas são percebidas como vozeadas.

${ }^{5}$ Os falantes de nível básico apresentaram mais casos de pausa do que os falantes dos outros níveis de proficiência porque, muitas vezes, não conseguiram produzir as frases do experimento de maneira contínua, mesmo quando solicitados para repeti-las sem a inserção de pausas.

\section{REFERÊNCIAS}

BISOL, L. (Org.). Introdução aos estudos de fonologia do português brasileiro. 4. ed. Porto Alegre: EDIPUCRS, 2005.

BOERSMA, Paul; WEENINK, David. Praat: doing phonetics by computer. (Versão 5.0.47) [Programa Computacional]. 2006. Disponível em: www.praat.org.

BROSELOW, E. e Y. KANG. Second language phonology and speech. In J. Herschensohn and M. Young-Scholten (eds.) The Cambridge Handbook of Second Language Acquisition, 529-554. Cambridge, MA: Cambridge University Press, 2013

ECKMAN, F. R. Markedness and the contrastive analysis hypothesis. Language Learning 27: 315-330, 1977.

FLEGE, J. E. Second Language Speech Learning: Theory, findings, and problems. In: STRANGE, W. (ed.). Speech perception and linguistic experience: Issues in cross-language research. Timonium, MD: York Press, 1995, p. 233-277, 1995 
FRIES, C. C. Teaching and learning English as a foreign language. Ann Arbor: University of Michigan Press., 1945.

GASS, Suzan M. \& SELINKER, Larry. Second Language Acquisition: An Introductory Course. Hillsdale, NJ: Lawrence Erlbaum Associates, 2008. 357p.

GUSSEnHOVEN, C.; JACOBS, H. Understanding Phonology. Londres: Arnold Publishers, 1998.

LADO, R. Linguistics across cultures. Ann Arbor: University of Michigan Press, 1957.

MAJOR, R. C. Transfer in Second Language Phonology. Phonology and Second Language Aquisition, 36, 63-94, 2008.

MAJOR, R. Foreign accent: The ontogeny and phylogeny of second language phonology. Mahwah,NJ: Lawrence Erlbaum Associates, 2001.

MATTOSO CÂMARA Jr., J. Estrutura da Língua Portuguesa. Petrópolis: Vozes, 1972.

MENDES, C. F. The Perception of the English -s Morpheme by Brazilian EFL learners. Dissertação de Mestrado. Florianópolis: Universidade Federal de Santa Catarina, 2017.

ROCA, I.; JOHNSON, W. A course in phonology. Oxford: Blackwell, 1999.

SILVA, C. C. Aquisição da Regra de Assimilação do Vozeamento em Português Brasileiro. Série: Produção Acadêmica Premiada. São Paulo: FFLCH/ USP, 2010.

SMITH, C. The devoicing of /z/ in American English: effects of local and prosodic context. Journal of Phonetics, v. 25, p. 471-500, 1997.

TRUBETZKOY, N. Princípios de Fonologia. In Travaux du Cercle Linguistique de Prague 7, 1939.

WEINREICH, U. Languages in contact. New York: Linguistic Circle of New York, 1953.

YAVAs, Mehmet. Applied English Phonology. Malden: Blackwell Publishers, 2006. 245p.

Recebido em: 30/04/2017

Aceito em:18/07/2017 